\title{
Evaluasi Struktur Gedung Student Centre dan Sport Centre STAIN Malang
}

\author{
Nur Achmad Husin \\ Program Diploma Teknik Sipil FTSP ITS \\ Email:husinits@gmail.com
}

\begin{abstract}
Student Centre and Sport Centre Building is part of the Campus Development Project STAIN Malang. At first, Student Centre and Sport Centre are 2 (two) separate building structures. In the development stage, Student Centre and Sport Centre are built as one structure. This condition causes the development funders of Campus STAIN (i.e. the Islamic Development Bank/IDB) request to evaluate the structure to determine the change to the safety of the building Sport Centre and Student Centre. Steps to analyze the structure of Student Centre and Sports Centre are separate building and structure Student Centre with Sport Centre as one structure. Evaluation results indicate the incorporation of the structure Student Centre and the Sport Centre produces a more rigid structure that is structurally safe.
\end{abstract}

Keywords: separated building structures, one structures, evaluation, safety

Abstrak

Student Centre dan Sport Centre merupakan bagian dari Proyek Pembangunan Kampus STAIN Malang. Pada awalnya Student Centre dan Sport Centre merupakan 2 gedung yang terpisah secara struktur. Didalam pembangunan Student Centre dan Sport Centre dibangun menjadi satu kesatuan struktur. Kondisi ini menyebabkan penyandang dana pembangunan Kampus STAIN yakni Islamic Development Bank $(I D B)$ minta dilakukan evaluasi struktur terhadap perubahan tersebut sebagai pertimbangan IDB terhadap keamanan struktur gedung Sport Centre dan Student Centre. Tahapan yang dilakukan adalah dengan melakukan analisa struktur Student Centre, Sport Centre secara terpisah dan struktur Student Centre dengan Sport Centre menjadi satu kesatuan struktur. Hasil Evaluasi menunjukkan penggabungan struktur Student Centre dan Sport Centre menghasilkan struktur menjadi lebih kaku sehingga aman secara struktur.

Kata Kunci : terpisah secara struktur, satu kesatuan struktur, evaluasi, keamanan

1. Pendahuluan

Student Centre dan Sport Centre merupakan bagian dari Proyek Pembangunan Kampus STAIN Malang secara keseluruhan. Pada awalnya Student Centre dan Sport Centre merupakan 2 gedung yang terpisah. Mengingat fungsinya yang menurut pertimbangan tertentu bisa disatukan maka Pemilik dalam hal ini Pihak
STAIN MALANG menginginkan agar kedua gedung tersebut dirancang menjadi satu kesatuan. Permintaan Pemilik akhirnya direspon oleh kontraktor dan semua pihak terkait sehingga terwujudlah kedua gedung yang semula terpisah tersebut akhirnya menjadi satu seperti terlihat saat ini dan gedung tersebut diberi nama Sport Centre and Student Centre Buildings. 
Sport Centre dan Student Centre Buildings tersebut mempunyai 2 fungsi yakni lantai 1 berfungsi sebagai Student Centre sedangkan lantai 2 berfungsi sebagai Sport Centre. Tampak dilapangan dibuatnya dilatasi pada kedua sisi memanjang bagunan sedangkan pada sisi melebar bangunan disatukan (tanpa dilatasi).

Kondisi ini menimbulkan keraguan pihak Islamic Development Bank (IDB) sebagai penyandang dana pembangunan gedung Student Centre dan Sport Centre, atas kekuatan dan kenyaman struktur pada saat menerima beban terutama beban gempa dan perbedaan penurunan.

Permasalahan yang saat ini muncul adalah berkaitan dengan penyatuan dua buah bangunan gedung yaitu Gedung Sport Centre dan Gedung Student Centre menjadi satu kesatuan struktur gedung, sehingga bagaimana kondisi bangunan tersebut apabila terkena beban gempa berkaitan dengan sisi memanjang bangunan yang dibuat dilatasi dan pada sisi melebar bangunan yang dibuat tanpa dilatasi.

Tujuan dari evaluasi Sport Centre and Student Centre Buildings yaitu untuk melakukan evaluasi struktur gedung Student Centre dan Sport Centre yang awalnya direncanakan terpisah kemudian dalam pelaksanaannya dibuat menjadi satu kesatuan struktur apabila menerima beban gempa.

Sebelum dilakukan evaluasi terhadap Sport Centre and Student Centre Buildings maka dilakukan peninjauan lapangan bersama pihak STAIN, Konsultan Perencana serta Kontraktor utama pembangunan Kampus STAIN. Dari pengamatan lapangan diperoleh beberapa hal terkaitan dengan keraguan pihak IDB terkait dengan disatukannya Gedung Sport Centre dan Student Centre yaitu :

1. Adanya dilatasi pada kedua sisi memanjang bangunan, sedangkan pada sisi melebar dibuat tanpa dilatasi.

2. Dalam waktu 3 bulan lebih tidak ditemukan indikasi retak khusus pada bagian melebar bangunan, kondisi ini menggambarkan kekawatiran terjadi differential Settlement yang tidak sama antara bangunan eksisting dengan bangunan tambahan ternyata tidak terjadi.
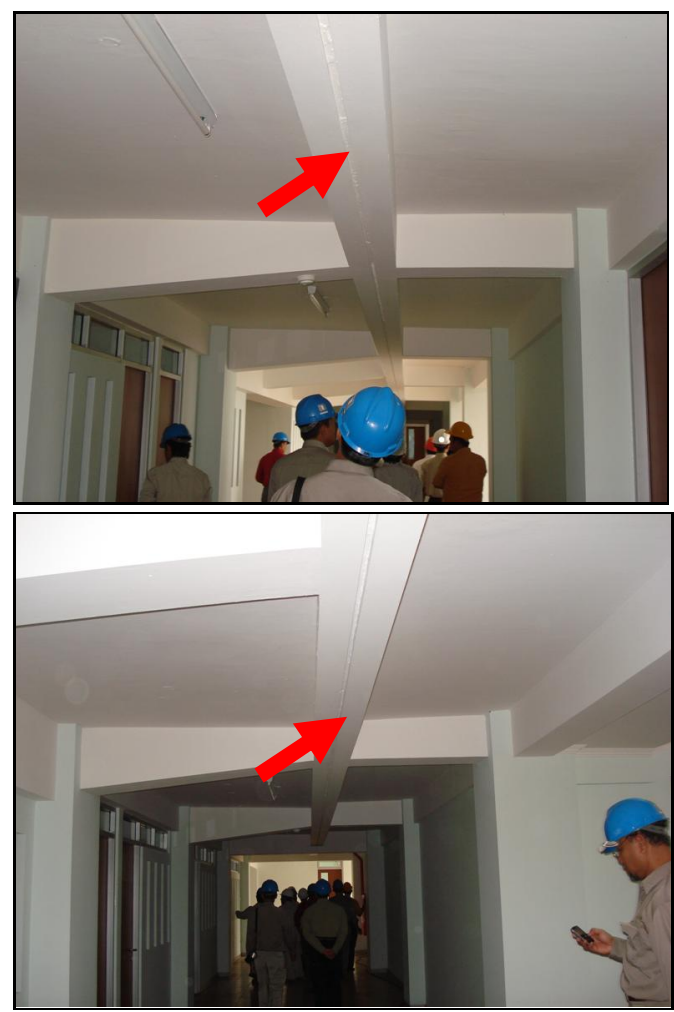

Gambar 1 : Dilatasi pada sisi memanjang bangunan di lantai 1 (Student Centre) 
2. Metodologi

Data Perencanaan yang digunakan untuk Sport Centre and Student Buildings adalah sebagai Berikut :

1. Panjang Bangunan $(\mathrm{L})=60 \mathrm{~m}$

2. Lebar Bangunan (B) $=40 \mathrm{~m}$

3. Elevasi Sport Centre $=+14.650$

4. Lokasi

$=$ Malang

5. Mutu beton (fc')

$=\mathrm{K}-275$

6. Mutu Tulangan (fy)

$=390 \mathrm{MPa}$

7. Tulangan Pelat

$=\mathrm{M} 7$

8. Beban Hidup

$=800 \mathrm{~kg} / \mathrm{m}^{2}$

9. Wilayah Gempa $=4($ Moderat $)$
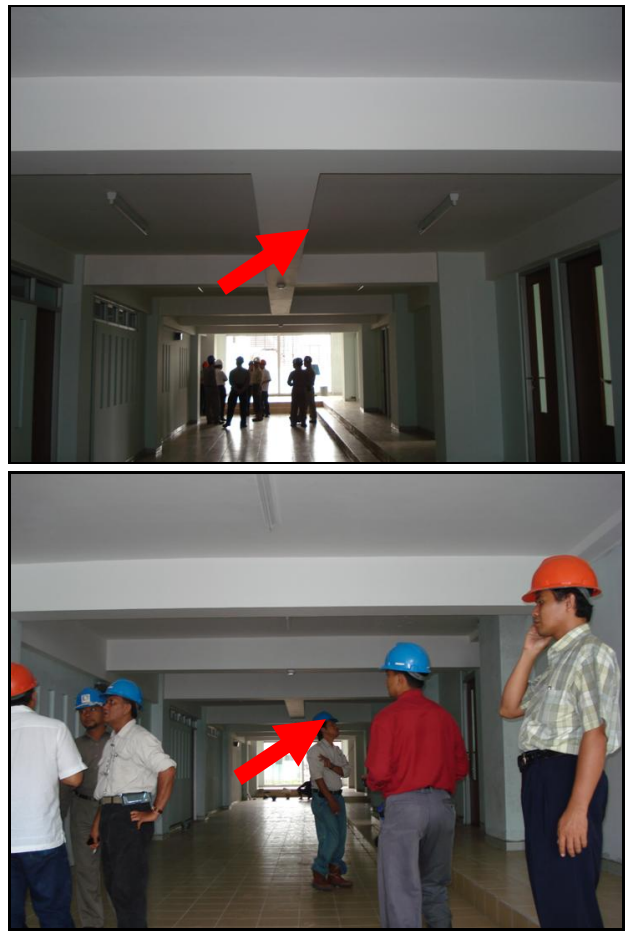

Gambar 2 : Bagian Melintang bangunan, yang dibuat tanpa dilatasi di lantai 1 (Student Centre)

10. Panjang Bangunan $(\mathrm{L})=60 \mathrm{~m}$

11. Lebar Bangunan (B) $\quad=40 \mathrm{~m}$

12. Elevasi Sport Centre $=+14.650$

13. Lokasi

$=$ Malang

14. Mutu beton (fc')

$=\mathrm{K}-275$

15. Mutu Tulangan (fy)

$=390 \mathrm{MPa}$

16. Tulangan Pelat

$=\mathrm{M} 7$

17. Beban Hidup
18. Wilayah Gempa $=4$ (Moderat)

Didalam pemodelan struktur Sport Centre and Student Buildings memodelkan Struktur sebagai open frame 3 dimensi yang beban-beban yang bekerja adalah meliputi :

a. Beban Mati

b. Beban Hidup

c. Beban Gempa Respons Spectrum
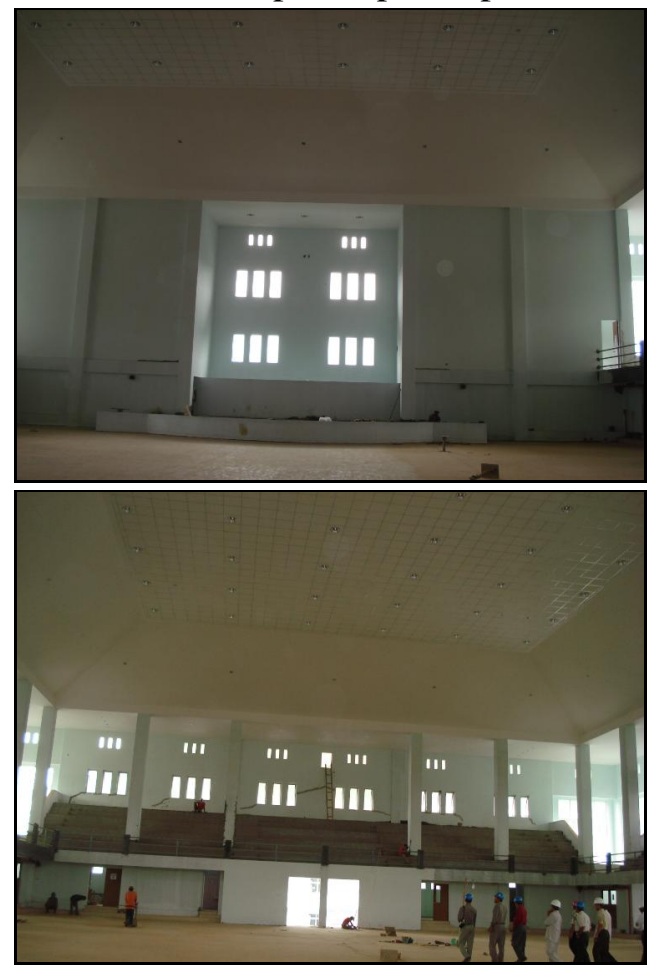

Gambar 3 : Bagian melintang bangunan, yang dibuat tanpa dilatasi di lantai 2 (Sport Centre)

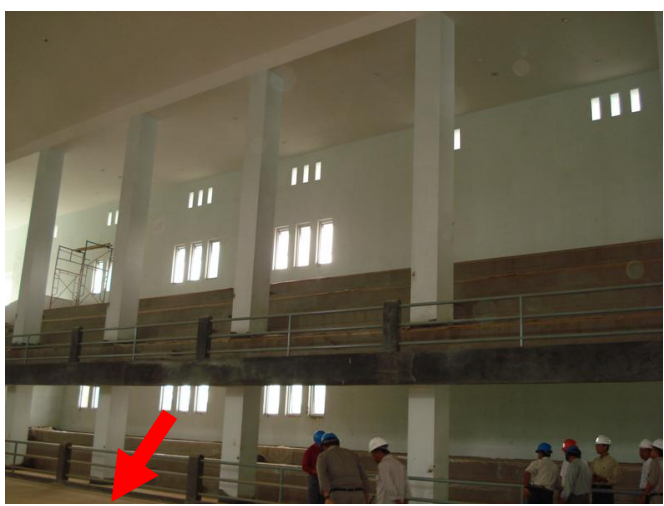

Gambar 4 : Bagian memanjang bangunan yang dibuat dengan dilatasi di lantai 2 (Sport Centre) 
Didalam pemodelan Sport Centre and Student Centre Buildings dilakukan dalam beberapa tahapan untuk memberikan gambaran defleksi yang kemungkinan akan terjadi pada saat gedung tersebut terkena beban gempa.

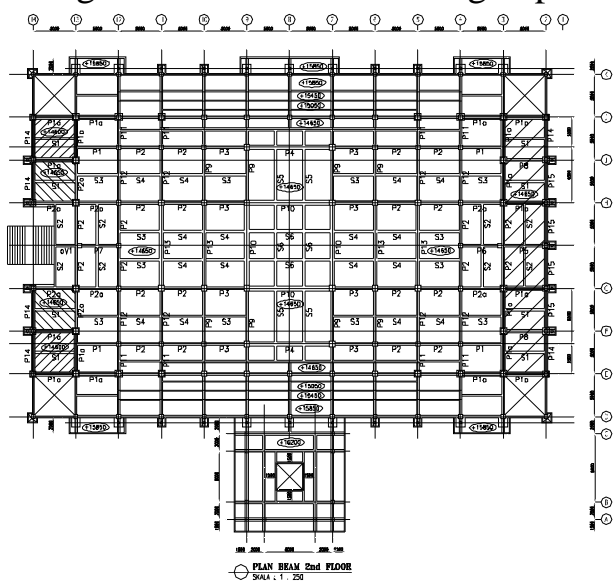

Gambar 5 : Denah Sport Centre dan Student Buildings

Hal ini dimaksudkan untuk mengamati secara detail setiap defleksi yang mungkin akan terjadi terkait dengan dilatasi yang ada. Adapun tahapan pemodelan dilakukan dalam 3 tahap meliputi :

1. Tahap 1

Pemodelan Bangunan sisi dalam saja yang merupakan bangunan tambahan dikontrol defleksinya akibat kombinasi beban mati + hidup + gempa.

2. Tahap 2

Pemodelan Bangunan eksisting sebelum diberi bangunan tambahan atau yang sebelumnya dikenal sebagai Sport Centre dikontrol defleksinya terhadap kombinasi beban mati + hidup + gempa.

3. Tahap 3
Pemodelan Bangunan gabungan atau yang dikenal Sport Centre and Student Centre Buildings dikontrol defleksinya akibat kombinasi beban mati + hidup + gempa .

3. Hasil dan Pembahasan

Analisa yang dilakukan terhadap bangunan Sport Centre and Student Centre yang digabung, dilakukan dalam 3 tahap untuk mendapatkan gambaran cukup detail mulai pada saat perencanaan awal sampai pada kondisi gabungan. Berikut ini ditunjukan analisa dan perhitungan terhadap kondisi struktur Sport Centre and Student Centre.

a. Analisis Tahap 1

Analisis awal dilakukan terhadap model Bangunan sisi dalam (bangunan Student Centre). Adapun pembebanan yang bekerja meliputi :

Beban mati

- Spesi $2 \times 22=44 \mathrm{~kg} / \mathrm{m}^{2}$

- Keramik 1,5 x $24=36 \mathrm{~kg} / \mathrm{m}^{2}$

- Ducting AC $\quad=19 \mathrm{~kg} / \mathrm{m}^{2}$

$=99 \mathrm{~kg} / \mathrm{m}^{2}$

Beban hidup $\quad=800 \mathrm{~kg} / \mathrm{m}^{2}$

Beban Gempa R = 5,5

Pemodelan struktur bangunan Student Centre ditunjukkan pada gambar 6 dan 7 berikut,

Halaman 26 J urnal APLIKASI: Media Informasi \& Komunikasi Aplikasi Teknik Sipil Terkini 


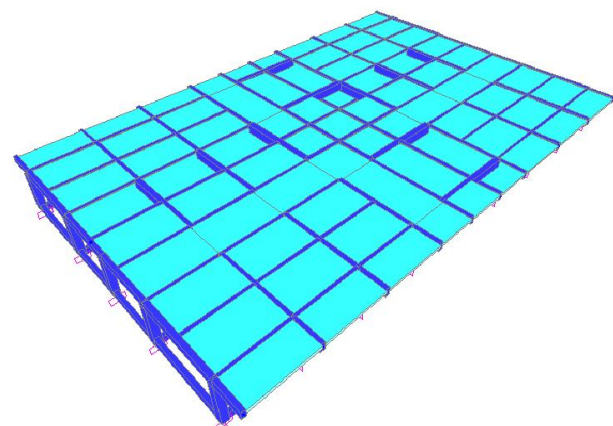

Gambar 6 : Pemodelan bangunan sisi dalam (Student Centre)

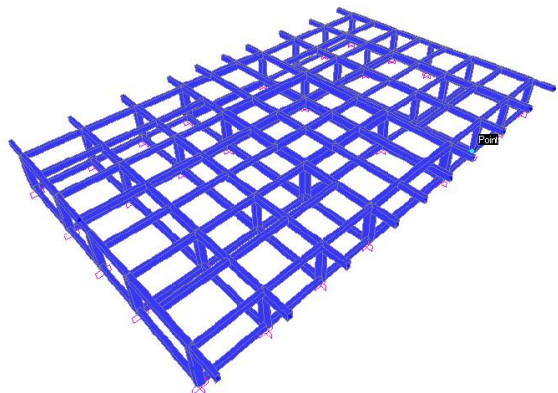

Gambar 7 : Pembalokan bangunan sisi dalam (Student Centre)

Dari pemodelan diatas diperoleh informasi mengenai defleksi maksimum yang terjadi pada bangunan Student Centre terhadap masing-masing sumbu baik sumbu $\mathrm{X}, \mathrm{Y}$ dan $\mathrm{Z}$ seperti terlihat pada Tabel 1, 2, dan 3.

Tabel 1. Defleksi Maksimum yang terjadi pada sumbu $\mathrm{X}$

\begin{tabular}{|c|c|c|c|c|c|c|}
\hline TABLE: Joint Displacements & & & & \\
\hline Joint & OutputCase & CaseType & StepType & U1 & U2 & U3 \\
\hline Text & Text & Text & Text & m & m & m \\
\hline 136 & D+L+RSX & Combination & Max & 0.00085 & 0.000251 & -0.000145 \\
\hline
\end{tabular}

Tabel 2. Defleksi Maksimum yang terjadi pada sumbu $\mathrm{Y}$

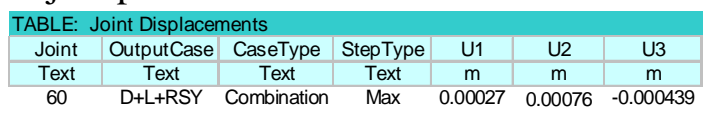

Dari tabel 1, 2, dan 3 tampak bahwa Defleksi maksimum terjadi terhadap ketiga sumbu $\mathrm{X}, \mathrm{Y}$ dan $\mathrm{Z}$ sebagai berikut :

1. Defleksi arah $X=0,85 \mathrm{~mm}$

2. Defleksi arah Y $=0.76 \mathrm{~mm}$

3. Defleksi arah $\mathrm{Z}=16,725 \mathrm{~mm}$

b. Analisis Tahap 2

Analisis kedua dilakukan terhadap model Bangunan sisi luar yang pada mulanya sebagai bangunan Sport Centre. Adapun pembebanan yang bekerja meliputi :

Beban mati

- Spesi 2 x 22

$$
=44 \mathrm{~kg} / \mathrm{m}^{2}
$$

- Keramik 1,5 x $24=36 \mathrm{~kg} / \mathrm{m}^{2}$

- Ducting AC

$$
=\frac{19 \mathrm{~kg} / \mathrm{m}^{2}}{99 \mathrm{~kg} / \mathrm{m}^{2}}
$$

Beban hidup

$$
=800 \mathrm{~kg} / \mathrm{m}^{2}
$$

Beban Gempa $\mathrm{R}=5,5$

Pemodelan struktur bangunan Sport Centre ditunjukkan pada gambar 8 dan 9 berikut,

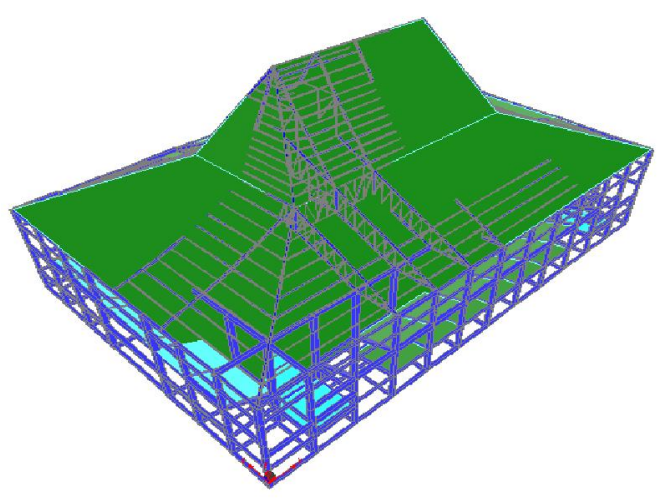

Gambar 8 : Pemodelan bangunan sisi luar (Sport Centre)

\begin{tabular}{|c|c|c|c|c|c|c|}
\hline & \multicolumn{6}{|c|}{ ement } \\
\hline Jolnt & UutputCase & CaseType & Step Type & U1 & U2 & U3 \\
\hline Text & Text & Text & Text & $\mathrm{m}$ & $\mathrm{m}$ & $\mathrm{m}$ \\
\hline 589 & $\mathrm{D}+\mathrm{L}+\mathrm{RSY}$ & Combination & Min & -0.0002 & -0.00063 & -0.016725 \\
\hline
\end{tabular}

Tabel 3. Defleksi Maksimum yang terjadi pada sumbu $\mathrm{Z}$ 


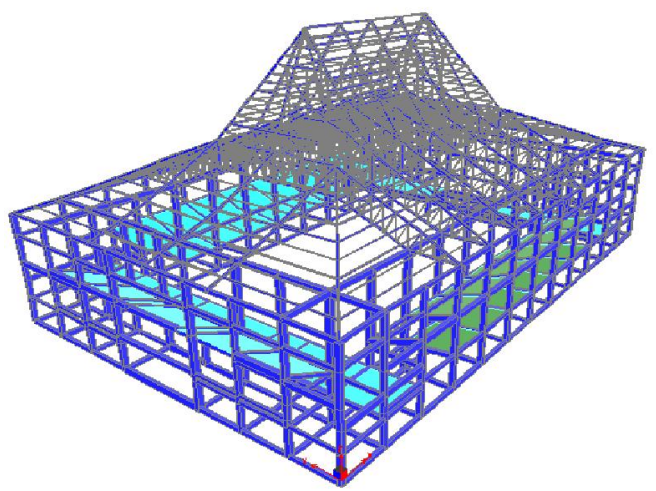

Gambar 9 : Bentuk Portal bangunan sisi luar (Sport Centre)

Dari pemodelan diatas diperoleh informasi mengenai defleksi maksimum yang terjadi pada bangunan Sport Centre terhadap masing-masing sumbu baik sumbu $\mathrm{X}, \mathrm{Y}$ dan $\mathrm{Z}$ sebagai berikut,

Tabel 4. Defleksi Maksimum yang terjadi pada sumbu $\mathrm{X}$

\begin{tabular}{|r|c|c|c|c|c|c|}
\hline \multicolumn{1}{|c|}{ TABLE: Joint Displacements } & & & & \\
\hline Joint & CutputCase & CaseType & StepType & U1 & UR & UB \\
\hline Text & Text & Text & Text & m & m & m \\
\hline 1895 & D+L+RSX & Combination & Max & 0.010132 & 0.002377 & -0.000217 \\
\hline
\end{tabular}

Tabel 5. Defleksi Maksimum yang terjadi pada sumbu $\mathrm{Y}$

\begin{tabular}{|r|c|c|c|c|c|c|}
\hline TABLE: Joint Displacements & & & & \\
\hline Joint & OutputCase & CaseType & StepType & U1 & UR & UB \\
\hline Text & Text & Text & Text & m & m & m \\
\hline 1865 & D+L+RSY & Combination & Max & 0.001441 & 0.007895 & -0.001307 \\
\hline
\end{tabular}

Tabel 6. Defleksi Maksimum yang terjadi pada sumbu $\mathrm{Z}$

\begin{tabular}{|c|c|c|c|c|c|c|}
\hline TABLE: & Joint Displacements & & & & \\
\hline Joint & OutputCase & CaseType & StepType & U1 & U2 & U3 \\
\hline Text & Text & Text & Text & m & m & m \\
\hline 609 & D+L+RSY & Combination & Min & -0.000513 & 0.000864 & -0.008211 \\
\hline
\end{tabular}

Dari tabel diatas tampak bahwa Defleksi maksimum terjadi terhadap ketiga sumbu $\mathrm{X}, \mathrm{Y}$ dan $\mathrm{Z}$ sebagai berikut :

1. Defleksi arah $\mathrm{X}=10,132 \mathrm{~mm}$

2. Defleksi arah Y $=7,895 \mathrm{~mm}$

3. Defleksi arah Z $=8,211 \mathrm{~mm}$

\section{c. Analisis Tahap 3}

Analisis ketiga dilakukan terhadap model Bangunan Gabungan Sport Centre dan Student Centre. Adapun pembebanan yang bekerja meliputi :

Beban mati

- Spesi $2 \times 22=44 \mathrm{~kg} / \mathrm{m}^{2}$

- Keramik 1,5 x $24=36 \mathrm{~kg} / \mathrm{m}^{2}$

- Ducting AC $\quad=19 \mathrm{~kg} / \mathrm{m}^{2}$

$=99 \mathrm{~kg} / \mathrm{m}^{2}$

Beban hidup $\quad=800 \mathrm{~kg} / \mathrm{m}^{2}$

Beban Gempa $\mathrm{R}=5,5$

Selanjutnya model struktur bangunan gabungan ditunjukkan pada gambar 10 dan 11 berikut,

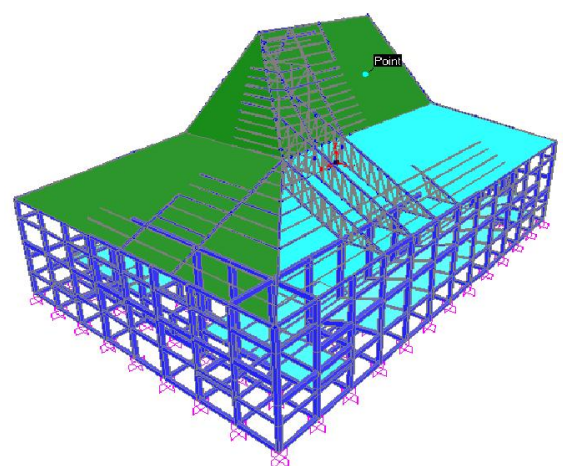

Gambar 10. Pemodelan bangunan gabungan Sport Centre dan Student Centre Buildings

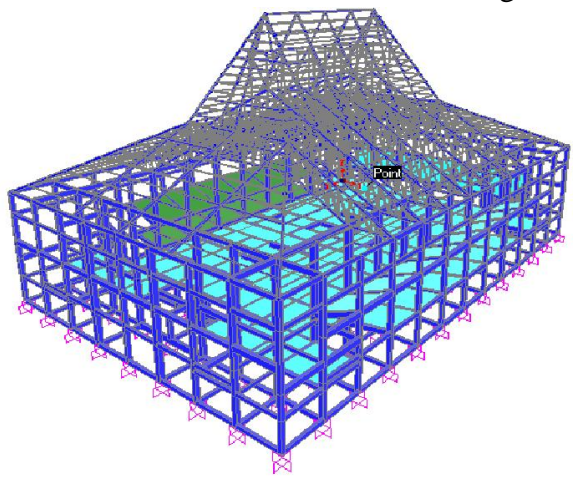

Gambar 11. Bentuk Portal bangunan gabungan Sport Centre dan Student Centre Buildings

Dari pemodelan diatas diperoleh informasi mengenai defleksi maksimum 
yang terjadi pada bangunan gabungan terhadap masing-masing sumbu baik sumbu X, Y dan Z sebagai berikut,

Tabel 7. Defleksi Maksimum yang terjadi pada sumbu $\mathrm{X}$

\section{TABLE: Joint Displacements}

Joint OutputCase CaseType StepType UI $\quad$ LR $\quad$ UB

\begin{tabular}{c|c|c|c|c|c|c}
\hline Text & Text & Text & Text & $m$ & $m$ & $m$ \\
\hline
\end{tabular}

186 D+L+RSX Combination $\mathrm{Mn} \quad-0.002276-0.000175-0.003816$

Tabel 8. Defleksi Maksimum yang terjadi pada sumbu $\mathrm{Y}$

\begin{tabular}{|l|c|c|c|c|c|c|}
\hline TABLE Joint Displacements & & & & \\
\hline Joint & OtputCase & CaseType & StepType & U1 & UR & UB \\
\hline Text & Text & Text & Text & m & m & m \\
\hline 1853 & DHL+RSY & Combination & Nax & 0.00013 & 0.002342 & -0.000113 \\
\hline
\end{tabular}

Tabel 9. Defleksi Maksimum yang terjadi pada sumbu $\mathrm{Z}$

\begin{tabular}{|c|cc|cc|cc|}
\hline TABLE: Joint Displacements & & & & \\
\hline Joint & OutputCase & CaseType & StepType & U1 & U2 & U3 \\
\hline Text & Text & Text & Text & m & m & m \\
\hline 590 & D+L+RSX & Combination & Min & -0.00042 & -0.000051 & -0.016573 \\
\hline
\end{tabular}

Dari tabel diatas tampak bahwa Defleksi maksimum terjadi terhadap ketiga sumbu $\mathrm{X}, \mathrm{Y}$ dan $\mathrm{Z}$ sebagai berikut :

1. Defleksi arah $\mathrm{X}=2,276 \mathrm{~mm}$

2. Defleksi arah Y $=2,342 \mathrm{~mm}$

3. Defleksi $\operatorname{arah} \mathrm{Z}=16,573 \mathrm{~mm}$

Dari ketiga tahapan analisa yang telah dilakukan diatas, kemudian hasil perhitungan defleksi yang diperoleh dievaluasi dengan memperhatikan persyaratan kinerja bangunan sesuai dengan pasal 8 SNI 03-1726-2002, yang dapat dijelaskan sebagai berikut.

Kinerja Bangunan Sport Centre and Student Centre yang dievaluasi terhadap persyaratan kondisi kinerja Batas Layan ditentukan oleh simpangan antar-tingkat akibat pengaruh Gempa Rencana, untuk membatasi terjadinya pelelehan baja dan peretakan beton yang berlebihan, di samping untuk mencegah kerusakan nonstruktur dan ketidaknyamanan penghuni dan terhadap persyaratan kondisi kinerja Batas Ultimit yang ditentukan oleh simpangan antar-tingkat akibat pengaruh Gempa Rencana yaitu dalam kondisi struktur gedung di ambang keruntuhan, yaitu untuk membatasi kemungkinan terjadinya keruntuhan struktur gedung yang dapat menimbulkan korban jiwa manusia dan untuk mencegah benturan berbahaya antar-gedung atau antar bagian struktur gedung yang dipisah dengan sela pemisah (sela delatasi). Besarnya batas layan dan batas ultimit dapat ditunjukkan pada perhitungan Tabel 10.

Tabel 10. Persyaratan Maksimal Simpangan Bangunan

\begin{tabular}{|l|c|c|}
\hline Simpangan & Batas Layan & $\begin{array}{c}\text { Batas } \\
\text { Ultimit }\end{array}$ \\
\hline \multirow{4}{*}{ Persyaratan } & $0.03 \times \mathrm{ht} / \mathrm{R}=$ & $0.020 \mathrm{x}$ \\
& $0.03 \times 2850 / 5.5$ & $\mathrm{ht}=$ \\
& $=15.55 \mathrm{~mm}$ & $0.02 \mathrm{x}$ \\
& Maks. $30 \mathrm{~mm}$ & $2850=$ \\
& & 57.00 \\
& & $\mathrm{~mm}$ \\
\hline Diputuskan & $15.55 \mathrm{~mm}$ & 57.00 \\
& & $\mathrm{~mm}$ \\
\hline
\end{tabular}

Dari ketiga tahapan diatas diperoleh informasi berkaitan dengan besarnya defleksi maksimum ang terjadi akibat penggabungan bangunan Sport Centre dan Student Centre kemudian dibandingkan dengan persyaratan defleksi arah horisantal baik kondisi layan maupun kondisi ultimit.

Berdasarkan hasil analisis yang ditampilkan pada Tabel 11 untuk bangunan tambahan (Student Centre) saja terlihat bahwa defleksi lateral 
maksimum yang diakibatkan beban gempa terhadap sumbu $\mathrm{X}$ dan $\mathrm{Y}$ sekitar $0.85 \mathrm{~mm}$ dan $0.76 \mathrm{~mm}$, sedangkan pengamatan terhadap bangunan Sport Centre saja akibat pembebanan gempa defleksi lateral maksimum arah $\mathrm{X}$ dan $\mathrm{Y}$ semakin membesar dibandingkan bangunan tambahan (Student Centre) yakni sebesar 10,132 dalam arah X dan 7,895 dalam arah Y. Apabila kedua bangunan Sport Centre dan Student Centre dibangun menjadi satu, maka defleksi lateral maksimum yang ditimbulkan semakin kecil akibat beban gempa sebesar yaitu 2,276 $\mathrm{mm}$ dalam arah $\mathrm{X}$ dan 2,342 mm dalam arah Y.

Tabel 11. Resume defleksi yang terjadi pada Sport Centre and Student Centre Buildings

\begin{tabular}{|c|c|c|c|c|}
\hline No & Arah & Tahap & Tahap & Tahap \\
1 & 2 & 3 \\
\hline 1 & $\begin{array}{c}\text { Arah } \\
\mathrm{X} \\
(\mathrm{mm})\end{array}$ & 0.85 & 10,132 & 2,276 \\
\hline 2 & $\begin{array}{c}\text { Arah } \\
\mathrm{Y} \\
(\mathrm{mm})\end{array}$ & 0.76 & 7,895 & 2,342 \\
\hline 3 & $\begin{array}{c}\text { Arah Z } \\
(\mathrm{mm})\end{array}$ & 16,725 & 8,211 & 16,573 \\
\hline
\end{tabular}

Besarnya defleksi lateral maksimum yang terjadi tersebut masih lebih kecil dari persyaratan kinerja bangunan baik untuk kondisi beban layan maupun beban ultimit sebagaimana ditunjukkan pada table 10, sehingga analisa tersebut semakin menguatkan hypotesa bahwa dengan penggabungan kedua bangunan tersebut justru akan terjadi kondisi struktur yang makin memperkaku dibandingkan bila kedua bangunan tersebut berdiri sendiri-sendiri.

4. Kesimpulan

Berdasarkan analisis di atas maka diperoleh beberapa kesimpulan kerterkaitan dengan disatukannya bangunan Sport Centre dan Student Centre sebagai berikut :

1. Penyatuan kedua bangunan tersebut seperti yang telah dilaksanakan saat ini semakin memperkaku bangunan apabila dibebani gempa, hal ini terlihat dengan semakin mengecilnya defleksi arah $\mathrm{X}$ dan arah Y. Indikasi ini menujukkan defleksi arah lateral $\mathrm{X}$ dan $\mathrm{Y}$ relative kecil.

2. Sistem Penggabungan Bangunan yang telah dilakukan pada bangunan Sport Centre dengan bangunan Student Centre mempunyai kekakuan yang cukup dalam menerima beban-beban yang bekerja terutama beban gempa untuk Wilayah Gempa 4 sesuai peraturan SNI 03-1726-2002, sehingga mempunyai kekuatan struktur yang cukup aman selama operasional.

3. Dari hasil pengamatan lapangan yang dilakukan, menunjukkan bahwa dalam kurun waktu 6 bulan lebih, tidak ditemukan indikasi adanya keretakan akibat penurunan bangunan, khususnya pada bagian melebar bangunan. Sehingga dengan kondisi ini dapat disimpulkan bahwa kekhawatiran terjadinya differential settlement (perbedaan penurunan) 


\section{ISSN. 1907-753X}

yang tidak bersama-sama antara

bangunan eksisting dengan

bangunan tambahan, tidak terjadi.

Daftar Pustaka

Badan Standarisasi Nasional. 1987.

Peraturan Pembebanan untuk

Gedung.

Badan Standarisasi Nasional. 2002.

Tata Cara Perencanaan Struktur

Beton untuk Bangunan Gedung.

Badan Standarisasi Nasional. 2002.

Tata Cara Perencanaan Ketahanan

Gempa untuk Bangunan Gedung. 
Halaman ini sengaja dikosongkan 